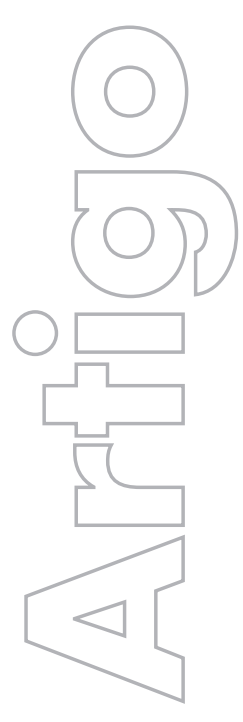

revista

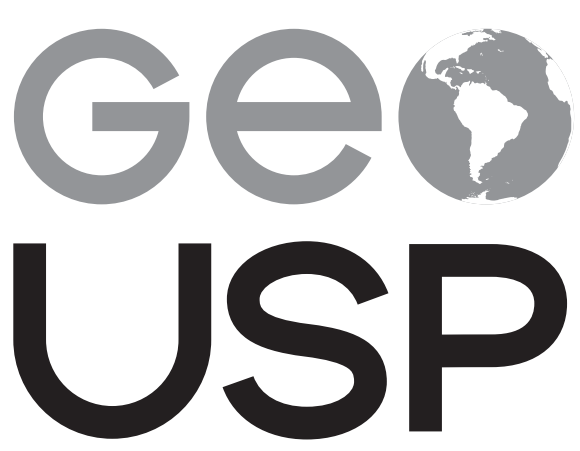

espaço e tempo

Volume $20 \cdot n^{\circ} 3(2016)$

ISSN 2179-0892

\section{Planejamento urbano} ambiental: diretrizes para o zoneamento na bacia do córrego do Limoeiro em Presidente Prudente-SP

\author{
Marcos Rodrigues Frois \\ Instituição Toledo de Ensino \\ de Presidente Prudente-SP
}

p. $619-635$
Como citar este artigo:

ARANA, A. R. A.; FROIS, M. R. Planejamento urbano ambiental: diretrizes para o zoneamento na bacia do córrego do Limoeiro em Presidente Prudente-SP. Geousp - Espaço e Tempo (Online), v. 20, n. 3, p. 619-635, mês. 2016. ISSN 2179-0892.

Disponível em: <http://www.revistas.usp.br/geousp/issue/ view/6465> . doi: http://dx.doi.org/10.11606/issn.2179-0892. geousp.2014.84539.

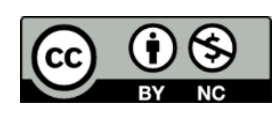

Este artigo está licenciado sob a Creative Commons Attribution 4.0 License. 


\title{
Planejamento urbano ambiental: diretrizes para o zoneamento na bacia do córrego do Limoeiro em Presidente Prudente-SP
}

\section{Resumo}

Este trabalho avalia o impacto ambiental da urbanização da bacia do córrego do Limoeiro, em Presidente Prudente-SP, com base nas políticas de planejamento adotadas para o ordenamento da cidade. Inventariou-se a bacia para compreender os aspectos físicos e geomorfológicos da área de estudo e identificar as principais características e usos dessa bacia hidrográfica, assim como seus problemas ambientais. A sistematização dos estudos culminou num mapa de diretrizes gerais de zoneamento e uso do solo, considerando as áreas de restrição ambiental e os valores de urbanidade.

Palavras-chave: Planejamento urbano e ambiental. Córrego do Limoeiro. Uso e ocupação do solo. Expansão urbana. Presidente Prudente-SP.

\section{Urban planning environment: guidelines for zoning in Limoeiro Stream Basin in Presidente Prudente-SP}

\begin{abstract}
This study aimed to evaluate the environmental impacts of urbanization of Limoeiro Stream Basin in Presidente Prudente SP, based on the evaluation of the planning policies that have been adopted for the organization of the city. It was an inventory of the basin, in order to understand the physical aspects and geomorphological study of the area, to make it possible to identify the main characteristics and uses of this river basin, as well as environmental problems. The systematization of the studies resulted in a map of general guidelines for zoning and land use, considering the areas of environmental restrictions and the values of urbanity.
\end{abstract}


Keywords: Urban and environmental planning. Limoeiro's Stream. Land use and occupation. Urban sprawl. Presidente Prudente-SP.

\section{Introdução}

Como consequência da expansão desordenada das cidades, surgem problemas ambientais nas áreas urbanas, que são ocasionados pela degradação dos recursos naturais (Soares; Leal, 2011). Desse modo, o processo de urbanização pode ser considerado como um agente de transformação da natureza.

É preciso considerar a importância da legislação ambiental que aborda as questões de inserção em ambiente urbano no tratamento da ocupação de fundos de vales em meio urbano. Nesse contexto, pode-se citar a Lei de Parcelamento de Solo (Brasil, 1979), as resoluções do Conselho Nacional do Meio Ambiente (Conama), o Código Florestal e a Constituição Federal de 1988. Esta última representou uma grande evolução, pois introduziu a questão da política urbana mediante o estabelecimento da obrigatoriedade do Plano Diretor e regulamentação da função social da propriedade.

Em razão de seu adensamento, muitas vezes a falta de planejamento no crescimento das cidades leva à ocupação de áreas de sensibilidade ambiental. Com isso, surgem problemas que exigem uma atuação em conjunto do planejamento e da gestão urbana. $\bigcirc$ planejamento urbano e ambiental é um instrumento importante na conservação e recuperação de áreas ambientais degradadas.

No caso do córrego do Limoeiro, foram insuficientes as medidas adotadas pelo poder para a proteção ambiental do corpo d'água como, por exemplo, o cercamento da APP (Área de Preservação Permanente). Ocorreram problemas ambientais constatados por meio de denúncias realizadas ao Ministério Público, como: danificação dos alambrados, utilização da área como pastagem, supressão da vegetação da APP, edificações invadindo a APP e deposição de resíduos sólidos em suas margens. $\bigcirc$ desrespeito por parte da população pode ser atribuído à falta de identificação com esse espaço residual.

Assim, este artigo tem o objetivo de discutir soluções para recuperar a bacia do córrego do Limoeiro, com base na importância da preservação dos recursos hídricos. E ainda a avaliar as consequências da urbanização das margens do córrego do Limoeiro. Isso pode ser alcançado por meio do planejamento e estabelecimento de diretrizes para a gestão integrada, garantindo um adequado ordenamento do uso e ocupação do solo urbano e por meio de propostas de adequação do uso de solo e identificação das áreas de restrição ambiental.

\section{Metodologia}

Para este trabalho, optou-se por uma análise da relação entre o planejamento urbano ambiental e a degradação ambiental. $\bigcirc$ planejamento ambiental constitui um dos instrumentos fundamentais para a proteção das águas e para orientar e subsidiar sua gestão. 
Leal (1995) aplica etapas adaptadas da metodologia de Mateo Rodriguez (1994) no Planejamento Ambiental. Essas etapas são dividas em inventário, diagnóstico ambiental, prognóstico e proposta.

Para Leal (1995), o inventário e diagnóstico do planejamento ambiental são um caminho para o entendimento das potencialidades e fragilidades das áreas de estudo, já que esse procedimento considera as variações temporais, espaciais e escalares. A elaboração de inventários é um meio de expor a situação real do objeto de estudo, tornando possível a compreensão da realidade local.

A etapa do Inventário consiste num levantamento detalhado do ambiente urbano da microbacia, considerando sua localização, o processo histórico de produção desse espaço e seus aspectos naturais e sociais, particularizados e inter-relacionados, de forma a obtermos unidades físicas, unidades de uso e ocupação do solo e unidades ambientais. (Leal, 1995, p. 47).

Com base nessas especificações, foi constituído um prognóstico da área que, de acordo com Leal (1995, p. 125), "consiste no estabelecimento de cenários futuros". Nesse sentido, aplicando esse conceito à pesquisa em questão, propuseram-se intervenções que conciliam as funções ambientais e urbanas, com base na previsão de cenários futuros.

Para o estudo dos aspectos físicos, foram consultados os trabalhos de Fushimi e Nunes (2011), que traz o mapa geomorfológico de Presidente Prudente; De Biasi (1992), que define os intervalos de declividade, os quais, por sua vez, determinam os limites estabelecidos pela legislação (como a Lei de Parcelamento do Solo e o Código Florestal); Soares e Leal (2011), que apresenta a carta clinográfica e a carta hipsográfica da bacia do córrego do Limoeiro, onde está localizado o Balneário da Amizade. Foram ainda utilizados os mapas disponíveis no plano de bacia e nos relatórios de situação de recursos hídricos do CBH-PP (Comitê de Bacias Hidrográfica do Pontal do Paranapanema); os mapas e cartas temáticas foram elaboradas utilizando os softwares ArcGis 9.2 e CorelDraw X3, com licenças disponíveis na, na escala 1:10:000.

$\bigcirc$ Balneário da Amizade está inserido na bacia do córrego do Limoeiro. Esse córrego está situado na divisa entre os municípios de Presidente Prudente e Álvares Machado (Figura 1). A escolha da bacia do Balneário da Amizade para o estudo reflete a preocupação com a recuperação ambiental e a conservação da área, em especial a represa do Balneário da Amizade, devido à sua importância a população local.

A bacia do Balneário da Amizade possui uma área de drenagem de $19,24 \mathrm{~km}^{2}$, tendo suas coordenadas geográficas $22^{\circ} 06^{\prime} 26,04^{\prime}$ S de latitude e 51²6’43,50"W de longitude. Está inserida na bacia do alto curso do córrego do Limoeiro, que por sua vez encontra-se na bacia hidrográfica do rio Santo Anastácio, na divisa dos municípios de Presidente Prudente e Álvares Machado, e na Unidade de Gerenciamento de Recursos Hídricos Pontal do Paranapanema. 


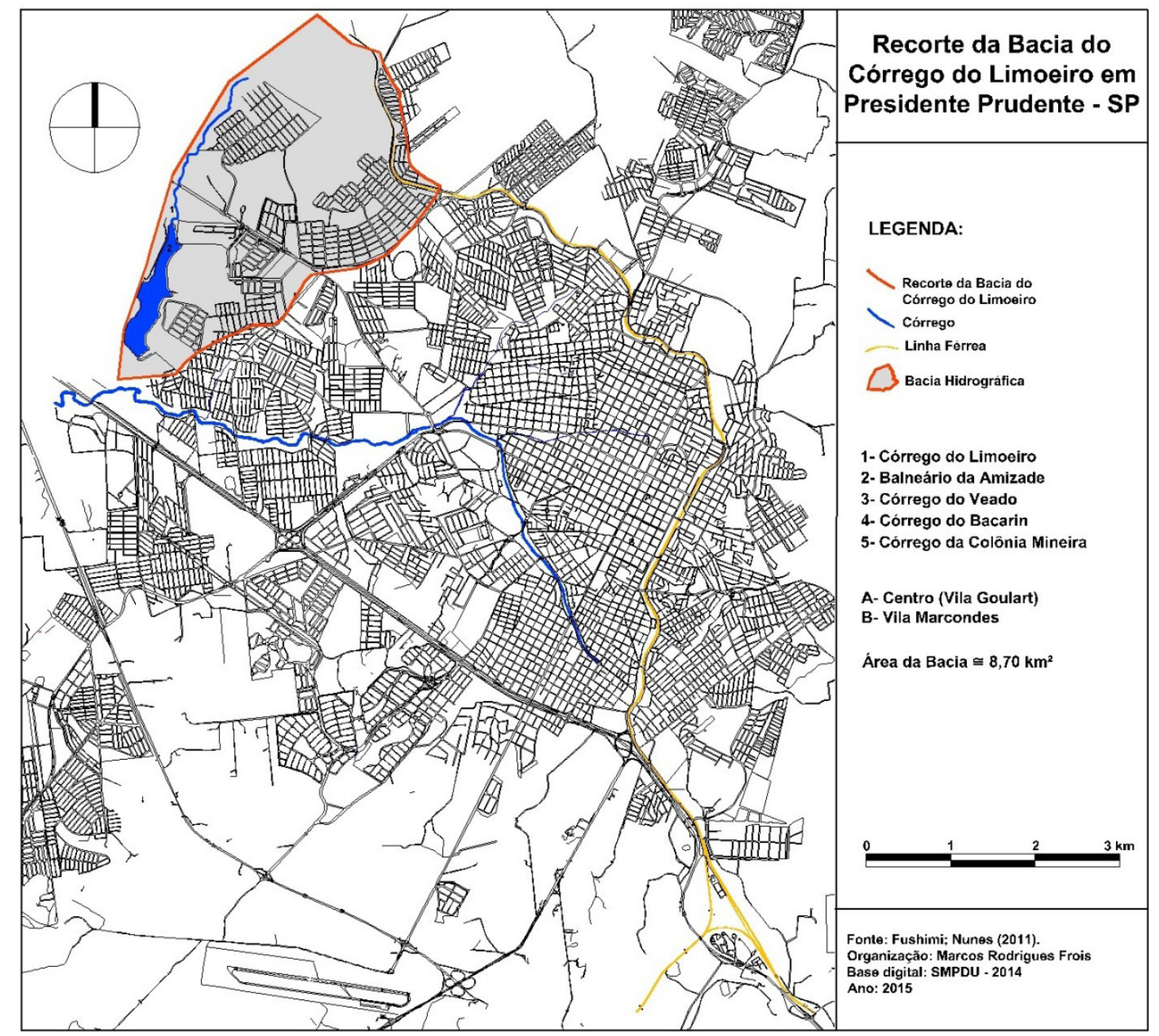

fonte: Mapa da Prefeitura Municipal de Presidente Prudente (Presidente Prudente, 2014). organização: Marcos Rodrigues Frois (2015).

Das atividades desenvolvidas, destacam-se trabalhos de campo para a coleta de informações, reconhecimento geral da área, entrevistas com os responsáveis pelos órgãos públicos municipais e visitas técnicas à área da bacia do córrego do Limoeiro para a caracterização e estudo de sua situação atual. O levantamento fotográfico da área foi feito a partir do trabalho de campo.

Para o estudo da ocupação da bacia do córrego do Limoeiro, foram realizadas visitas à Secretaria Municipal de Patrimônio e Desenvolvimento Urbano (SMPDU), de modo que foi possível ter acesso à base de dados da aprovação dos loteamentos, que continham as respectivas datas de implantação. Os dados necessários para elaboração do mapa de ocupação da área da bacia do córrego do Limoeiro foram complementados por meio do trabalho de Sposito (1995) e pelo acervo dos autores.

Nessa etapa preliminar do inventário, após a elaboração do Mapa Base, inicia-se a construção da elaboração do mapa de diretrizes do zoneamento da bacia do córrego do Limoeiro, determinando cinco zonas de conservação ambiental (ZCA) para a bacia. 


\section{Ocupação da bacia do córrego do Limoeiro}

Uma forma de compreender a dinâmica de ocupação da bacia do córrego do Limoeiro é por meio da relação dos loteamentos implantados. Os dados ordenados com base nas datas de implantação dos loteamentos foram espacializados para a elaboração do mapa de ocupação da área. Para a delimitação dos loteamentos, consultaram-se as plantas disponibilizadas na base virtual de Mapas e Informações Geográficas da prefeitura de Presidente Prudente (2014) sendo complementado por intermédio do trabalho de Sposito (1995). Consideraram-se os anos de implantação, de aprovação ou de planta do loteamento, nessa ordem de prioridade.

Na Figura 2, verifica-se que a ocupação da área teve início com a implantação de um loteamento desconectado à malha urbana consolidada. É necessário considerar os impactos da urbanização de áreas de várzea, em espacial nessa área caracterizada pela sensibilidade ambiental, em decorrência da suscetibilidade à erosão e à presença de nascentes hídricas.

\section{Figura 2 - Mapa de estudo da ocupação da bacia do córrego do Limoeiro em Presidente Prudente-SP}

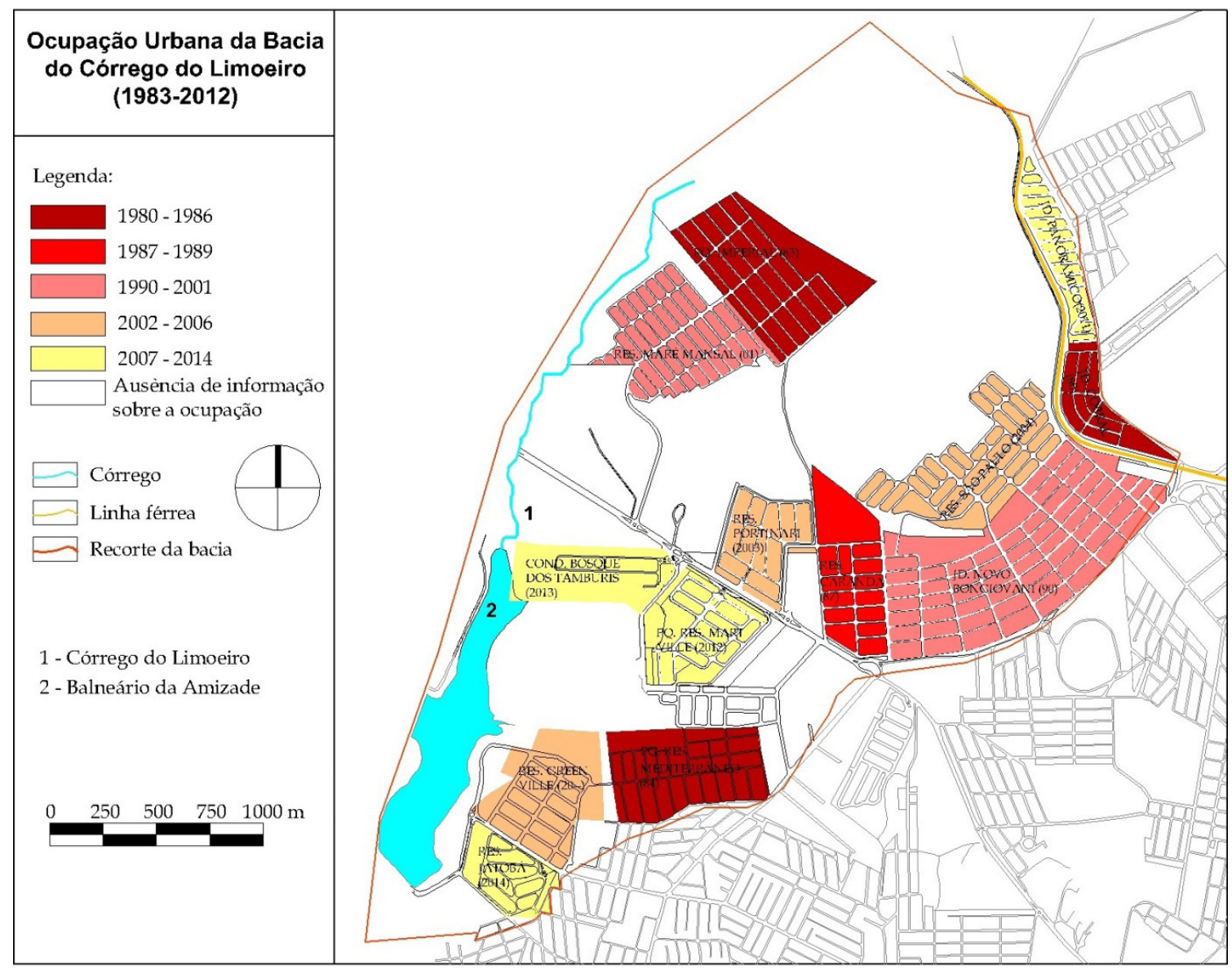

elaboração: Marcos Rodrigues Frois (2015) com base em dados da SMPDU (Presidente Prudente, 2014) e Sposito (1995).

Inicialmente, houve uma ocupação nos espigões da bacia. Esta configuração inicial propicia o espraiamento da malha urbana, com base na constituição de áreas vazias em seus interstícios. Esse tipo de ocupação não otimiza um crescimento compactado. 
Somente a partir da década de 1990 que os loteamentos começaram a ser implantados contíguos aos existentes, como é o caso do Jardim Novo Bongiovani (1990), que foi localizado imediatamente ao lado do Res. Carandá (1987). A partir dos anos 2000, a área começou a ser ocupada por loteamentos fechados. Esse processo se iniciou com a implantação do Residencial Portinari, em 2003.

Assim como ocorre em tantas outras cidades, Melazzo (1993) assinala que a especulação imobiliária influencia o desenho e o crescimento da cidade. A expansão territorial incorpora áreas novas descontínuas à malha urbana, em detrimento do crescimento com base na compacidade.

A urbanização da área ainda não foi completamente consolidada, o que se comprova pela constituição de um vazio urbano. Nesse sentido, ainda existem áreas não ocupadas que podem ser ordenadas com base em um planejamento adequado (Figura 3).

\section{Figura 3 - Vazio urbano e a rede hídrica}

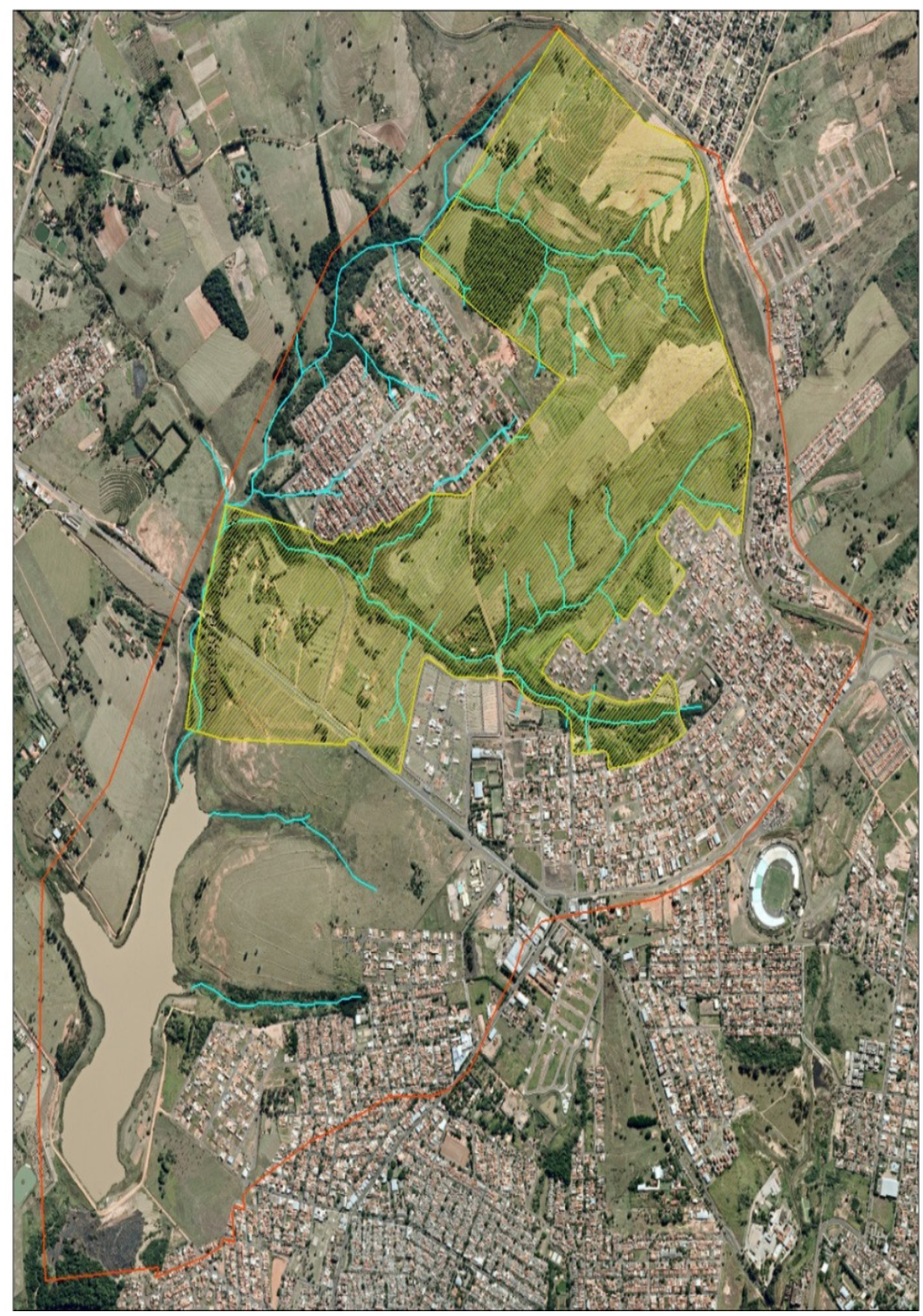

fonte: Google Earth, modificado por Marcos Rodrigues Frois (2015). 
É preciso considerar que o vazio urbano demarcado na Figura 3 foi valorizado em função da ocupação das terras circunvizinhas. Dessa forma, apesar de ter características que limitem sua ocupação, em razão dos impactos ambientais que a urbanização ocasionaria à dinâmica hídrica da bacia, não é improvável que a especulação imobiliária encontre artifícios para que essas terras também sejam densamente ocupadas, em detrimento de um planejamento adequado à bacia, desconsiderando os devidos valores ambientais.

Antes do início da ocupação dessa área estudada, pode-se afirmar que existia uma barreira psicológica que impedia sua urbanização, em virtude das próprias características do terreno (topográficas, com declividades acentuadas), da distância em relação ao centro (já que a área está situada no limite do perímetro urbano da cidade) e, ainda, por sua fragilidade ambiental. No entanto, essa barreira foi rompida quando isso se tornou interessante aos agentes de produção do espaço urbano (que podem ser públicos ou privados).

É comum, a partir do momento em que um empresário (comerciante, promotor imobiliário etc.) rompe a barreira, aquela área antes isolada do domínio psicológico do cidadão urbano, passar a ser aceita pelo senso comum. Esta mudança de atitude frente aquele espaço, outrora pouco considerado, pode ser desencadeada por uma campanha publicitária que ressalte outros aspectos positivos daquela área como arborização, fácil acesso, silêncio etc. (Sposito, 1995, p. 13).

Nesse sentido, o início da ocupação da área já rompeu com uma possível barreira psicológica que pudesse existir para impedir sua urbanização. Não será incomum que essa ocupação continue, alcançando a consolidação da urbanização. Essas considerações levam à necessidade de propor diretrizes urbanísticas para ocupar essa área, de modo a minimizar o impacto ambiental, mediante estabelecimento de índices urbanísticos mais rígidos, que viabilizem maior permeabilidade do solo e proteção efetiva das nascentes e de seus afluentes, que são responsáveis pela contribuição do fluxo de água e do equilibrio hídrico.

A constituição dos vazios urbanos demonstra uma falha quanto ao planejamento, que não considerou o crescimento adequado da cidade ao aprovar loteamentos desconectados da malha urbana. A aprovação de um novo loteamento não é um direito estabelecido, pois a prefeitura municipal tem o poder de analisar o projeto e determinar se ele será adequado ao crescimento da cidade. No entanto, interesses do mercado imobiliário influenciam negativamente neste julgamento. Leite (2012) afirma que a cidade deve planejar seu crescimento e não ser refém dele.

\section{Situação e caracterização da área}

Soares e Leal (2011) caracterizam que o cenário encontrado na área da represa do Balneário da Amizade era de degradação ambiental, deficiência quanto a ações políticas e à falha de gestão pública no tratamento dessa área.

[...] possui em sua represa artificial um cenário de degradação ambiental e precárias ações políticas, [...] pessoas que se utilizam do local, mesmo sem infraestrutura para atividades de lazer e obtendo a qualidade da água de seu manancial comprometida. Também são encontrados locais na bacia utilizados como descartes de resíduos sólidos e resíduos de construção e demolição (RCD). (Soares; Leal, 2011, p. 4).

Foi verificada a deposição de resíduos sólidos numa via não pavimentada marginal ao córrego do Limoeiro (Figura 4). Isso pode ocasionar prejuízos ambientais, já que esses resíduos provavelmente serão carreados para o córrego com a ocorrência de chuvas, poluindo suas águas. 


\section{Figura 4 - Proximidades das margens do córrego do Limoeiro}

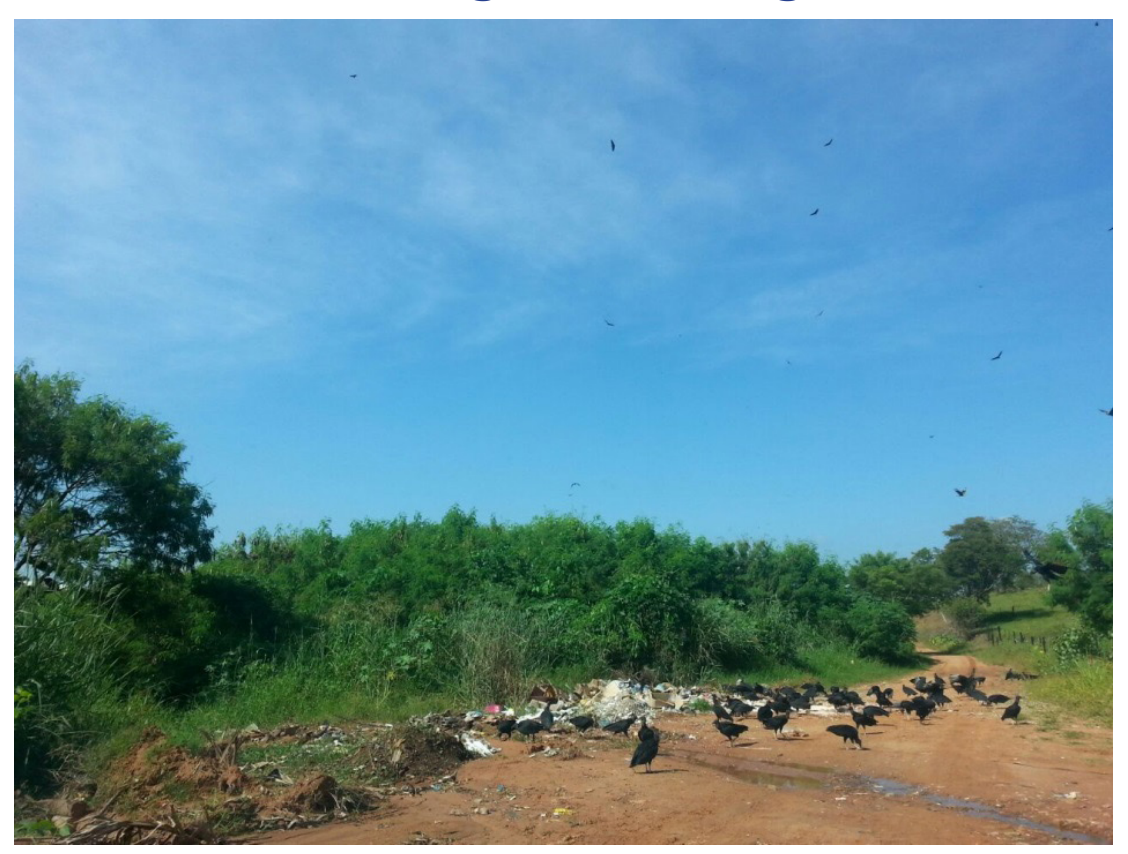

fonte: Acervo de Marcos Rodrigues Frois (2015).

Nesse contexto, é possível concluir que existe uma influência antrópica negativa na área do córrego do Limoeiro, expressa pela deposição inadequada de resíduos sólidos próximos ao leito do córrego, além, dos prejuízos ocasionados pela urbanização da área, como a impermeabilização do solo. Esses impactos geram consequências na dinâmica hídrica da bacia, como a alteração do fluxo de água do córrego, prejudicando o equilíbrio hidrológico.

Portanto, a implantação do Residencial Maré Mansa e Parque Imperial influenciou a dinâmica hídrica da bacia em função da drenagem das nascentes e da impermeabilização do solo. Em visitas à área desses loteamentos (Figura 5), foi possível observar que, no espaço onde estavam as nascentes, atualmente há edificações de alta densidade populacional.

As áreas das nascentes desses afluentes foram descaracterizadas em virtude da ocupação urbana. De acordo com Felippe e Magalhães Jr. (2009, p. 2), "a ocupação urbana ocasiona inúmeras alterações espaciais e ambientais e, consequentemente, na dinâmica hídrica”.

Nesse sentido, os autores apontam que, além do desaparecimento ou da degradação de nascentes, a impermeabilização causada pela ocupação urbana altera o equilibrio hidrológico da bacia, gerando consequências negativas ao sistema hídrico como: alteração das condições de infiltração da água fluvial e impedimento da exfiltração das águas subterrâneas; aumento da quantidade e da velocidade do escoamento superficial; redução da recarga dos aquíferos; intensificação dos processos erosivos; aumento da carga sedimentar para os cursos d'água; assoreamento e inundações.

A preservação das nascentes tem um papel fundamental na conservação do equilibrio hidrológico da bacia, já que elas são responsáveis por manter os corpos d'água perenes. Apenas em 1989, por intermédio da Lei n. 7.803 (Brasil, 1989), definiu-se uma proteção específica das nascentes. Por meio dessa alteração no Código Florestal, instituiu-se um raio mínimo de 50 metros de APP para as nascentes. Assim, as nascentes obtiveram um raio de proteção maior do que o próprio corpo d'água, no caso de rios menores que 10 metros de largura. Isso demonstra um reconhecimento da importância de proteção das nascentes, já que sua distância em relação aos equipamentos urbanos influencia o nível de impacto ambiental no sistema hídrico. 
Figura 5 - Análise da ocupação urbana

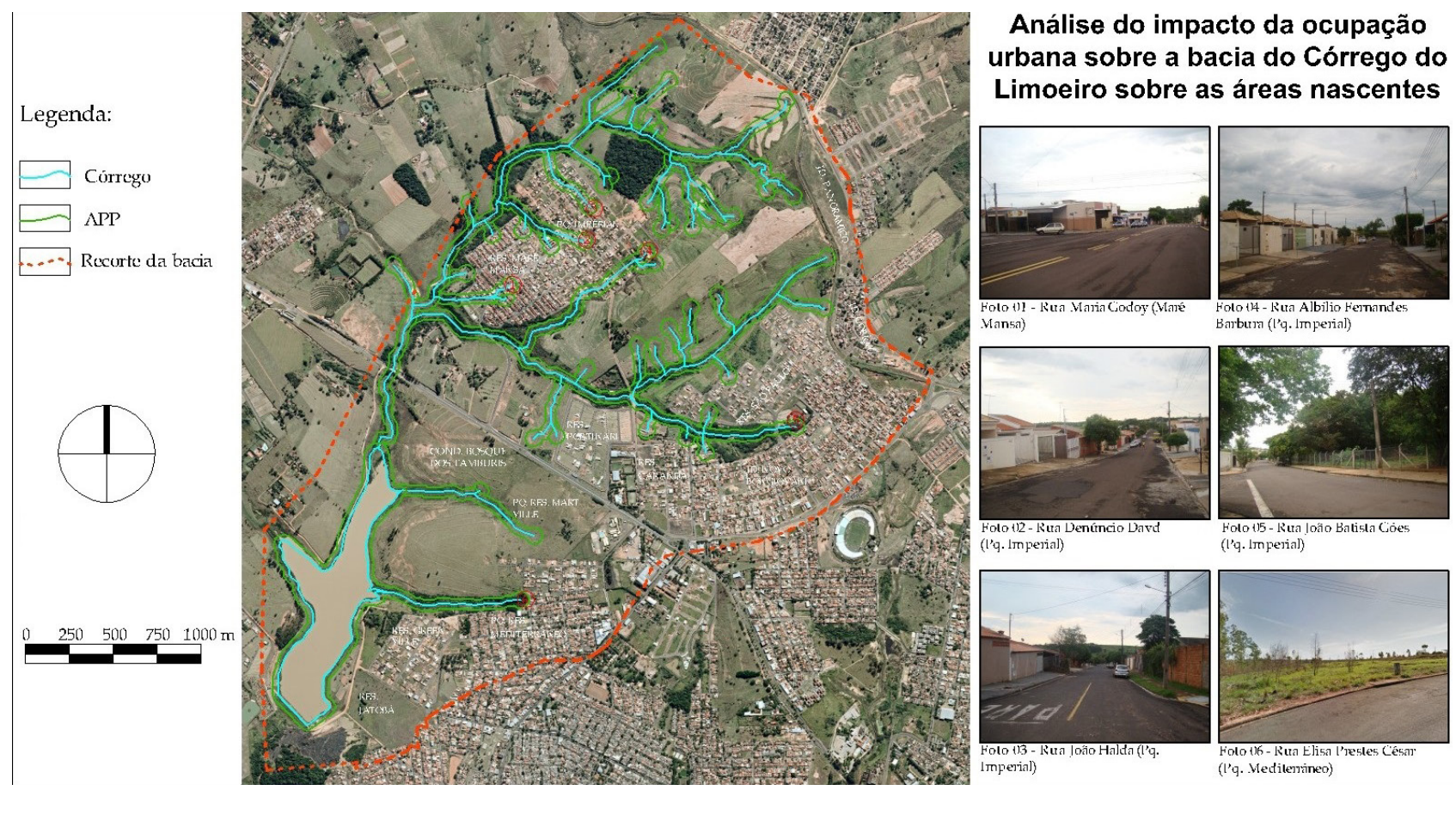

fonte: Google Earth, modificado por Marcos Rodrigues Frois (2015).

Nesse sentido, considera-se que a relação entre o grau de impermeabilização e a proximidade das nascentes determina a qualidade do sistema. Os impactos urbanos na bacia serão tanto maiores quanto mais expressiva for verificada essa relação.

É preciso avaliar a relação entre a ocupação urbana e a legislação vigente. $\bigcirc$ mapa da Figura 6 foi elaborado considerando quatro períodos:

$\checkmark$ 1980-1985: o período é marcado pelo início da ocupação da bacia (o Jardim Cobral corresponde ao primeiro loteamento implantado, em 1980). Nesse período, a Lei n. 4.771 (Brasil, 1965) ainda determinava 5 metros de APP. A partir de 1979, a promulgação da Lei n. 6.766/79 (Brasil, 1979) estabeleceu 15 metros de APP em área urbana para a aprovação de novos loteamentos. Para a confecção do mapa de estudo, considerou-se a norma que se constitui como mais restritiva e mais específica, 1 no caso, a Lei de Parcelamento do Solo (Brasil, 1979).

$\checkmark$ 1986-1988: o início desse período é marcado pela promulgação da Lei n. 7.511 (Brasil, 1986), que alterou a metragem estabelecida pelo Código Florestal de 5 metros para 30 metros de APP.

$\checkmark$ 1989-2011: o início do período é marcado pela promulgação da Lei n. 7.803 (Brasil, 1989). Nessa alteração do Código Florestal, se determinou que a APP deveria ser medida a partir do ponto mais alto, o que não era especificado na legislação anterior e também determinou-se a proteção específica das nascentes, instituindo um raio mínimo de 50 metros de APP para as nascentes dos corpos hídricos.

$\checkmark$ 2012-2014: o início desse período é marcado pela promulgação da Lei n. 12.651/12 (Brasil, 2012), popularmente conhecida como "Novo" Código Florestal. Essa Lei não alterou a metragem da faixa de proteção estabelecida, mantendo os 30 metros

1 Baseando no princípio da especialidade (Lex specialis de rogat legi generali), considera-se que a norma especial afasta a incidência da norma geral. 
de APP, no entanto, com a sua promulgação, a APP deveria ser medida a partir do leito regular do corpo d'água. Essa alteração não pôde ser observada no esquema do estudo da ocupação urbana (Figura 6), em razão da largura do córrego do Limoeiro, no entanto, em córregos maiores, essa alteração pode levar o próprio corpo d'água a ficar fora da proteção legal em épocas de cheia.

Pela Figura 6, é possível verificar a supressão de nascentes e afluentes hídricos em virtude da urbanização da área. Como, desde o início da ocupação da bacia, já estava vigente a proteção dos corpos hídricos e suas faixas lindeiras, por meio do Código Florestal (Brasil, 1965) e Lei de Parcelamento do Solo (Brasil, 1979), a supressão desses afluentes não pode ser atribuída a uma deficiência da legislação. Isso indica que muitas vezes, são utilizados artifícios que burlam a proteção dessas áreas, de modo que se verifica a urbanização em detrimento dos valores ambientais.

\section{Figura 6-Ocupação urbana da bacia do córrego do Limoeiro: APP e legislação}

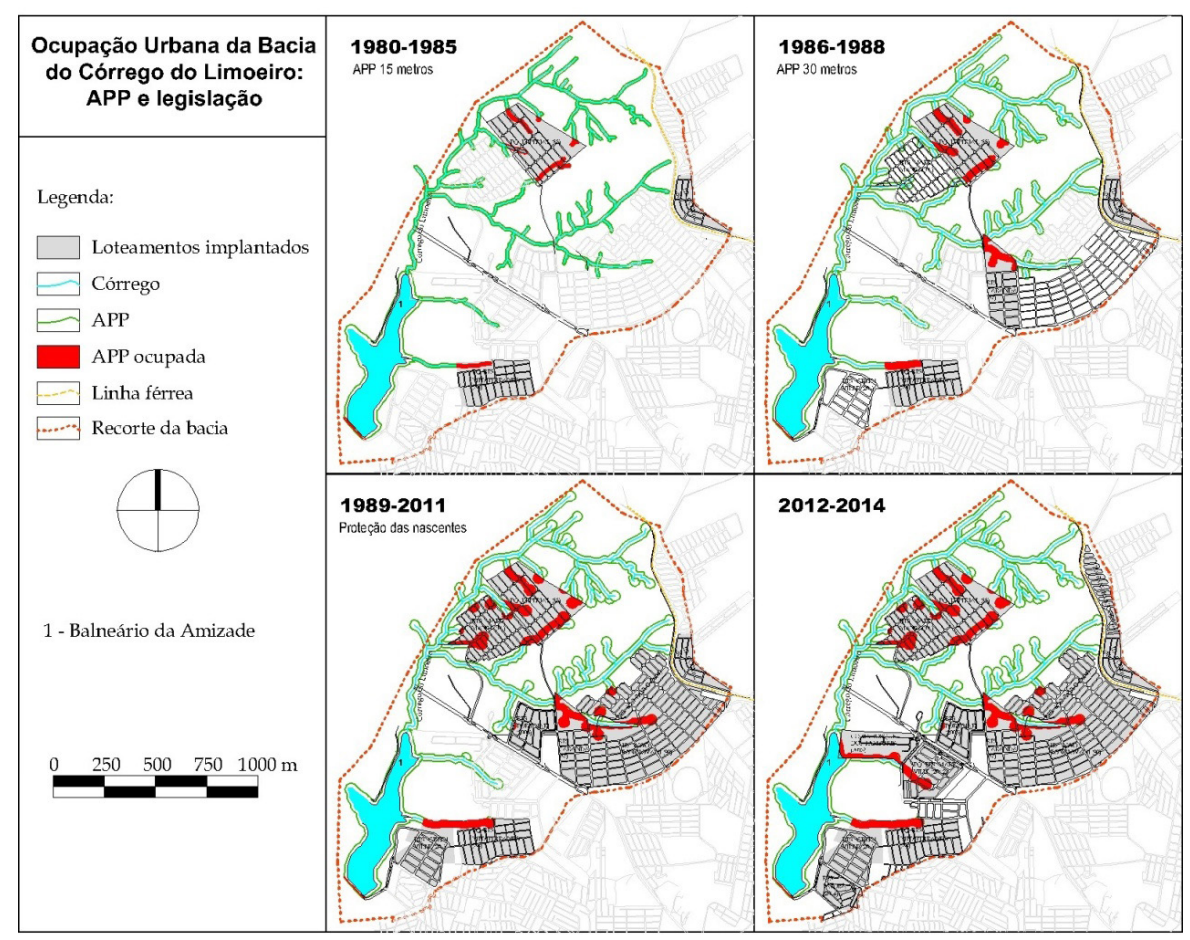

fonte: Presidente Prudente (2014).

elaboração: Marcos Rodrigues Frois (2015).

A impermeabilização e o aterramento de nascentes prejudicam a drenagem urbana. A impermeabilização do solo reduz a infiltração e aumenta o escoamento superficial, sobrecarregando algumas áreas, o que pode ocasionar alagamentos. Nesse sentido, a implantação do Residencial Maré Mansa e do Parque Imperial gerou inúmeros problemas de ordem ambiental, já que além da drenagem dos afluentes hídricos, a impermeabilização de áreas próximas ao córrego do Limoeiro influencia no equilibrio hídrico da bacia. Apesar do cercamento da APP, que foi um recurso usado para preservar essa área, os processos de degradação decorrentes da urbanização não foram evitados.

Isso demonstra que não houve identificação entre a população e esse espaço que deveria ser conservado, que se tornou espaço residual. Não foi realizado um trabalho de conscientização ambiental que possibilitasse que a população criasse um vínculo positivo com o córrego e sua APP. A proteção legal pode não ser suficiente para que as margens de cursos d'água sejam conservadas, já que quando elas ficam abandonadas em meio urbano, geram uma situação de degradação. 
A falta de contato entre a população e o córrego afasta a possibilidade de identificação entre eles, impedindo que a população se torne guardiã do corpo d'água, que assim lhe é estranho. Obviamente, não haverá valorização de um elemento desconhecido. É possível que a falta de contato ao invés de evitar a degradação, seja responsável por ela, já que impossibilita a valorização desse espaço.

\section{Zoneamento da bacia do córrego do Limoeiro}

A área do córrego do Limoeiro é caracterizada pela vulnerabilidade ambiental, em virtude do grande número de nascentes hídricas, o que aumenta a suscetibilidade à erosão. Analisando o mapa de zoneamento (Figura 7), é possível concluir que, além da área determinada para a APP, não se estabeleceu uma relação que considere as questões ambientais decorrentes das áreas caracterizadas pela sensibilidade ambiental.

A porção correspondente à parte sul do recorte da bacia, onde está o Balneário da Amizade, foi definida como ZRl (zona residencial 1), mais restritiva, com taxa de ocupação (TO) máxima de 50\%. Nesse sentido, é possível entender que o Balneário foi considerado na determinação do uso e na ocupação do solo, já que foi atribuída a essa porção um zoneamento mais restritivo.

\section{Figura 7 - Recorte do Mapa de Zoneamento de Presidente Prudente}

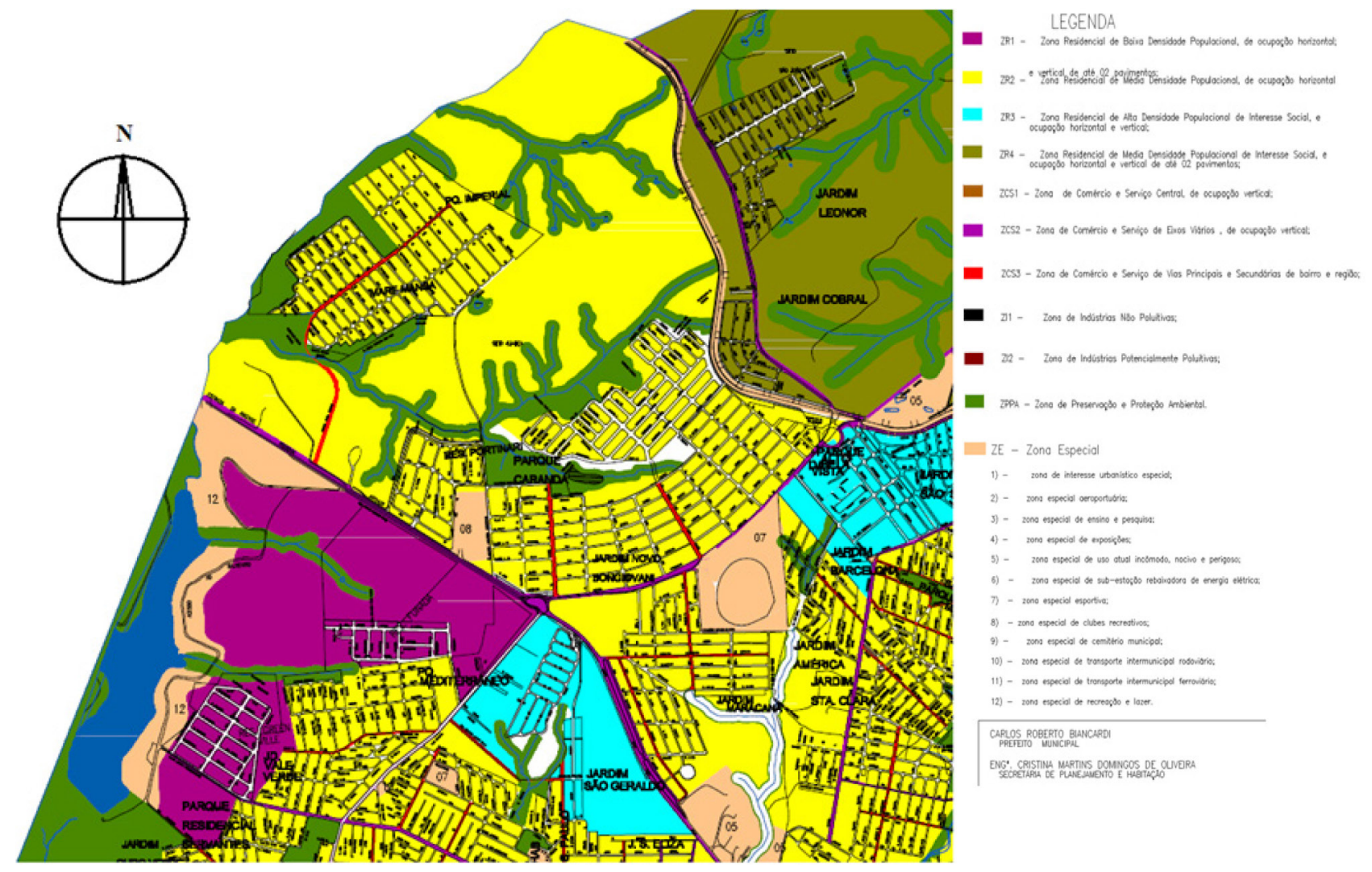

fonte: Presidente Prudente (2008).

No entanto, na parte norte do recorte da bacia foram atribuídas as normas de ocupação correspondentes à ZR2 (zona residencial 2), menos restritiva (TO máxima de 70\%). O grande número de afluentes hídricos nessa porção não foi considerado na determinação das normas urbanísticas. Uma alta densidade de ocupação pode ser negativa, pois reduz os índices de per- 
meabilidade do solo, prejudicando a eficiência de infiltração das águas superficiais, aumentando a "impermeabilidade e compactação do solo, dificultando ou mesmo impedindo a infiltração e retenção de água no subsolo, fazendo com que a velocidade de escoamento das águas pluviais seja consideravelmente maior" (Francisco et al., 2014, p. 11).

\section{Diretrizes de zoneamento na bacia do córrego do Limoeiro}

Com base no estudo realizado sobre a situação atual da ocupação do solo urbano, com enfoque na área da bacia do córrego do Limoeiro, constatou-se que existem certas deficiências no modelo de ocupação adotado. A flexibilidade que é verificada no estabelecimento das normas urbanísticas é influenciada pelos interesses decorrentes do mercado imobiliário. As zonas que são estabelecidas no atual mapa de zoneamento (Presidente Prudente, 2008) não foram determinadas, no geral, com base nos aspectos ambientais de cada compartimento de relevo.

Para a elaboração do mapa de diretrizes do zoneamento da bacia do córrego do Limoeiro (Figura 8), se consideraram os seguintes aspectos: a identificação das áreas de restrição ambiental, as próprias APP, os aspectos geomorfológicos, o desenho dos loteamentos, as áreas já ocupadas e os vazios urbanos, as zonas de compensação ambiental e o zoneamento atual.

Os compartimentos geomorfológicos, que expressam áreas com características físicas próximas, devem ser considerados no estabelecimento das normas urbanísticas de ocupação do solo urbano (Pedro, 2009). Foram propostas diretrizes de ordenamento da ocupação do solo urbano, utilizando os compartimentos de relevo como base para a determinação das zonas de incidência, já que, desta forma, é possível determinar áreas com características físicas próximas. Os compartimentos de relevo são estabelecidos no trabalho de Fushimi e Nunes (2011) e classificados em três gêneros: topo suavemente ondulado das colinas convexizadas (400 a 480 m), domínio das vertentes convexo-côncavas e retilíneas (340 a 400 m) e planícies aluviais e alvéolos (290 a 340 m).

\section{Figura 8 - Diretrizes para o Zoneamento da bacia do córrego do Limoeiro}

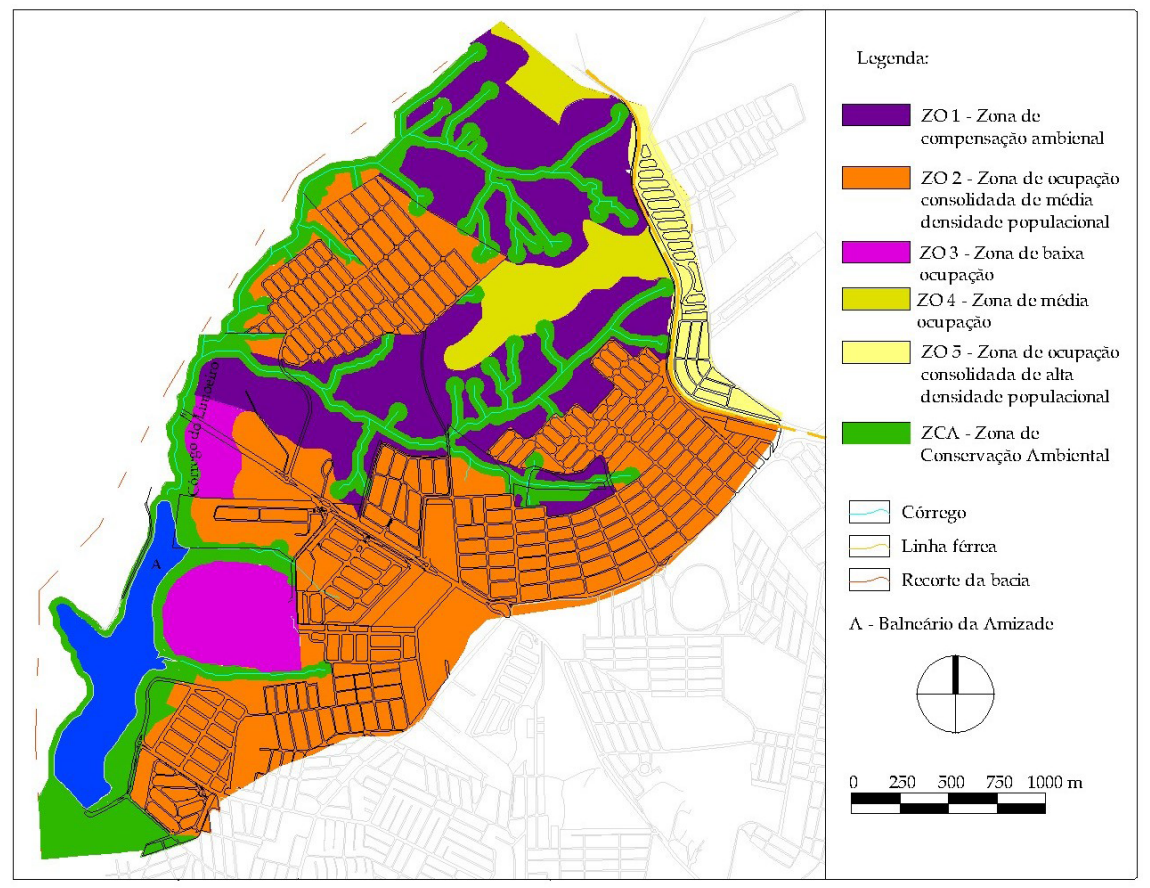

elaboração: Marcos Rodrigues Frois (2015). 
De acordo com essa classificação, é possível perceber que, no primeiro caso, a situação é mais propícia à ocupação pela menor probabilidade de acúmulo de água; o segundo caso deve ser considerado de baixa ocupação, por constituir maior fragilidade ambiental em relação ao caso anterior, sendo, o último caso citado, correspondente às áreas dos corpos d'água e sua APP, a situação mais crítica, em que a ocupação deve ser evitada.

Nesse sentido, as áreas de maior concentração de água devem ser consideradas na ocupação, já que constituem uma maior fragilidade ambiental. Os pontos de maior concentração de água podem ser determinados por intermédio das linhas de vertentes côncavas, que são concentradoras de fluxo de água pluvial. Essas zonas de maior fragilidade ambiental devem possuir índices urbanísticos mais rígidos e restritivos, para limitar a ocupação. Deve ser incentivada nessas áreas uma maior taxa de permeabilidade do solo.

Para a determinação das zonas de conservação ambiental (ZCA) foram consideradas as APP e as planícies aluviais e alvéolos. Neste trabalho, considerou-se uma faixa de conservação com uma demarcação mínima de 30 metros. Apesar de existirem legislações vigentes que estabeleçam demarcações menores (a Lei de Parcelamento do Solo determina 15 metros de APP para a aprovação de novos loteamentos), entende-se que a norma mais restritiva, nesse caso, é mais adequada, em virtude do âmbito ambiental. As planícies aluviais e alvéolos, que são determinados no trabalho de Fushimi e Nunes (2011, p. 13), devem ser incorporados às ZCA, pois, mesmo quando estão fora da demarcação da APP, são "locais favoráveis ao acúmulo de água durante certos períodos do ano". Nesse sentido, essas áreas têm alta fragilidade ambiental, e sua ocupação é inadequada não só devido aos prejuízos ambientais, mas também aos que podem causar à própria população, se for efetivada a urbanização dessas áreas, em virtude da possibilidade de inundação.

A infraestrutura verde é uma boa alternativa para intervenção em áreas consolidadas, já que se trata de variações do sistema de drenagem urbano e pode ser conciliada com qualquer sistema implantado. As biovaletas são valetas condutoras de água que absorvem e filtram a água. Suas dimensões variam de acordo com o local a ser implantado. No caso estudado, baseou-se no dimensionamento de canaletas de concreto, adaptando as estruturas para uma biovaleta.

Já os jardins de chuva são um elemento que tem como função principal a infiltração da água no solo, tem dimensões maiores que as Biovaletas, e deve ser implantado associado a valetas ou Biovaletas (Francisco et al., 2014, p. 14)

A ZOl (zona de compensação ambiental 1) corresponde a vazios urbanos que devem permanecer sem ocupação. Recomenda-se a conservação dessas áreas por serem caracterizadas por vazios urbanos com alta incidência de nascentes e corpos d'água. Entendeu-se que essa zona é necessária até mesmo como um sistema de compensação à bacia do córrego do Limoeiro, devido à ocupação de áreas inadequadas, com a drenagem de córregos e consequente descaracterização das APP. Recomenda-se que seja explorada na ZOl a implantação de sistemas de lazer e contemplação. Nesse sentido, um bom exemplo de utilização seria a construção de parques com arborização ornamental, de modo que contribua para configuração paisagística desse espaço, além do incentivo a atividades sustentáveis, que podem ser realizadas por meio da construção de pistas de caminhada e ciclovias. 
Salienta-se, nesse caso de intervenção em áreas de fragilidade ambiental, a importância da utilização do tipo de material adequado, que devem ser permeáveis e estáveis, para favorecer um sistema de drenagem adequado e evitar o carreamento de materiais.

Existem algumas áreas, como no caso da implantação do Residencial Maré Mansa e Parque Imperial, em que o corpo d'água foi drenado e a APP ocupada e impermeabilizada. Nessa situação, se verifica uma desconsideração das questões ambientais. No entanto, não é possível propor a desocupação dessas áreas já consolidadas, uma vez que, além de ser economicamente inviável, essa ação seria muito impactante, devido aos inúmeros prejuízos à população que seria desalojada, mesmo que houvesse sua realocação.

As áreas já ocupadas que têm maior fragilidade ambiental constituíram a ZO2 (zona de ocupação consolidada de média densidade populacional 2). Em razão da existência de córregos drenados e APP suprimidas nessa porção, propõe-se medidas paliativas para compensar os danos ambientais já existentes. Nesse sentido, para as áreas consolidadas, é possível implantar um sistema de infraestrutura verde, como jardins de chuva e biovaletas, a fim de otimizar o sistema de drenagem. Nesse contexto, Francisco e outros (2014, p. 14) apresentam as vantagens e características da implantação de infraestrutura verde para as áreas consolidadas:

Na ZO3 (zona de baixa ocupação 3) deve ser mantida uma ocupação com baixa densidade populacional. Sua demarcação corresponde, no geral, aos domínios das vertentes côncavo-convexo e retilíneas. Essa zona é passível à ocupação, no entanto, com certas reservas quanto aos índices urbanísticos que devem ser estabelecidos. Recomenda-se que seja atribuída uma TO máxima de 40\% nessa área, com taxa de permeabilidade mínima de 40\%.

Nas áreas de topo das colinas convexizadas que ainda não estão ocupadas indicou-se que a ocupação seja de média densidade populacional, configurando a ZO4 (zona de média ocupação 4). Indica-se que esse índice se torne mais restritivo que o determinado atualmente, com o estabelecimento de uma TO máxima de 50\% e taxa de permeabilidade de 30\%.

Por fim, a ZO5 (zona de ocupação consolidada de alta densidade populacional) constitui uma área de ocupação consolidada, no entanto, por estar implantada nas áreas de topo suavemente ondulado das colinas convexizadas, que consiste no componente geomorfológico de menor concentração de água pluvial, a densidade habitacional pode ser maior.

Estabelecendo-se um paralelo entre o zoneamento atual e a remodelação das diretrizes do zoneamento de uso e ocupação da bacia do córrego, as áreas já ocupadas - cujos lotes foram constituídos com base em índices urbanísticos menos restritivos - não sofreram muitas mudanças, já que é inviável alterar edificações já consolidadas. No entanto, foram previstas medidas paliativas que minimizam os impactos ambientais. Foi possível estabelecer índices urbanísticos mais adequados nas áreas que ainda não estão ocupadas, considerando os devidos aspectos ambientais. Nesse sentido, as áreas vazias propiciariam a criação, até mesmo, de um mecanismo de compensação às áreas que já foram ocupadas inadequadamente. Assim, entende-se que seria possível alcançar o equilibrio entre a ocupação urbana e os aspectos ambientais.

Ainda, outro ponto que deve ser considerado é o sistema viário. Por ser inviável a reformulação das áreas já ocupadas, é possível propor diretrizes mais claras para a constituição das vias nas áreas ainda não ocupadas. Como a ocupação da área da bacia do córrego do Limoeiro, que ainda não está totalmente consolidada, existe um potencial para a formulação de diretrizes 
para a ocupação dos espaços ainda não ocupados. A dimensão dos lotes das áreas ainda não ocupadas também deve ser considerada, já que lotes muito pequenos estimulam uma ocupação mais densa, o que propicia maior impermeabilização do solo.

\section{Considerações finais}

Existe uma fragilidade na legislação ambiental quanto às áreas inseridas no perímetro urbano, com base na relação conflituosa advinda das várzeas em ambientes urbanos, devido à desarticulação das legislações ambientais e urbanísticas. Esse conflito permite que haja exploração do solo sem a devida consideração dos aspectos ambientais e, até mesmo, dos próprios valores de urbanidade.

Com base na análise do zoneamento atual de Presidente Prudente (Presidente Prudente, 2008), verificaram-se certas fragilidades no uso e na ocupação do solo. Assim, foi possível perceber que não se consideram, de maneira adequada, as questões ambientais na determinação do zoneamento. Isso acontece porque, muitas vezes, o aspecto econômico do lucro decorrente da ocupação de terras se sobrepõe à necessidade de reserva de áreas para garantir o equilibrio ecológico. E, ainda, na bacia do córrego do Limoeiro, existem casos de corpos d'água drenados e APP descaracterizadas devido à implantação de alguns loteamentos.

Mediante o estudo da área, elaborou-se uma proposta alternativa com diretrizes para o zoneamento da bacia do córrego do Limoeiro, de modo que oriente a ocupação. Dessa forma, procurou-se compensar a ocupação inadequada existente por meio de medidas paliativas (como, por exemplo, a compensação no IPTU para incentivar lotes com maiores índices de permeabilidade). Não estando a ocupação urbana da bacia completamente consolidada, a existência de terras desocupadas permite que se implantem medidas de planejamento mais efetivas, mantendo desocupadas as áreas de maior sensibilidade ambiental e determinando adequadamente novos índices urbanísticos para as áreas passíveis de ocupação.

É preciso valorizar os espaços de várzea inseridos em ambientes urbanos, já que o crescimento das cidades os incorpora ao perímetro urbano. Nesse sentido, essa situação de fundos de vales urbanizados se tornará cada vez mais recorrente. Este trabalho contribui para a discussão de alternativas que orientem a ocupação dessas áreas.

\section{Referências}

BRASIL. Lei n. 12.651, de 25 de maio de 2012. Regulamenta os arts. 182 e 183 da Constituição Federal, estabelece diretrizes gerais da política urbana e dá outras providências. Diário Oficial da União, Brasilia, DF. Disponível em: http://www.planalto.gov.br/ ccivil_03/_ato2011-2014/2012/lei/112651.htm. Acesso em: 20 jul. 2015.

. Lei n. 7.803, de 18 de julho de 1989. Altera a redação da Lei n. 4.771, de 15 de setembro de 1965, e revoga as Leis n. 6.535, de 15 de junho de 1978, e n. 7.511, de 7 de julho de 1986. Diário Oficial da União, Brasília, DF. Disponível em: http://www.planalto. gov.br/ccivil_03/leis/L7803.htm. Acesso em: 20 mar. 2015. 
Lei n. 7.511, de 7 de julho de 1986. Altera dispositivos da Lei n. 4.771, de 15 de setembro de 1965, que institui o novo Código Florestal. Diário Oficial da União, Brasilia, DF. Disponível em: http://www.planalto.gov.br/ccivil_03/leis/17511.htm. Acesso em: 20 mar. 2015.

Lei n. 6.766, de 19 de dezembro de 1979. Dispõe sobre o Parcelamento do Solo Urbano e dá outras providências. Diário Oficial da União, Brasilia, DF. Disponível em: http://www.planalto.gov.br/ccivil_03/leis/L6766.htm. Acesso em: 20 mar. 2015.

Lei n. 4.771, de 15 de setembro de 1965. Institui o novo Código Florestal. Diário

Oficial da União, Brasilia, DF. Disponível em: http://www.mma.gov.br/port/conama/legiabre.cfm?codlegi=311. Acesso em: 20 mar. 2014.

DE BIASI, M. Carta clinográfica: os métodos de representação e sua confecção. $\mathbf{R D G}-\mathbf{R e -}$ vista do Departamento de Geografia da USP, São Paulo, n. 6, p. 45-60, 1992.

FELIPPE, M. F; MAGALHÃES JR., A. P. Consequências da ocupação urbana na dinâmica das nascentes e Belo Horizonte-MG. In: ENCONTRO NACIONAL SOBRE MIGRAÇÕES, 6., 2009, Belo Horizonte. Anais... Belo Horizonte: UFMG, 2009. p. $1-19$.

FRANCISCO, A. M. et al. Repensando os espaços da cidade: diretrizes urbanísticas para áreas de preservação permanente urbana consolidadas. In: SEMINÁRIO NACIONAL SOBRE O TRATAMENTO DE ÁREAS DE PRESERVAÇÃO PERMANENTE EM MEIO URBANO, 3., 2014, Belém. Anais... Belém: UFPA, 2014. p. 1-18.

FUSHIMI, M.; NUNES, J. O. Geomorfologia do município de Presidente Prudente-SP, Brasil. Revista Geográfica de América Central, Heredia- CR, v. 2, n. 47E, p. 1-16, 2011. Disponível em: http://www.revistas.una.ac.cr/index.php/geografica/article/view/2617. Acesso em: 25 mar. 2015.

\section{LEAL, A. C. Meio ambiente e urbanização na microbacia do Areia Branca Cam-} pinas, SP. Dissertação (Mestrado em Geociências e Meio ambiente) - Instituto de Geociências e Ciências Exatas, Universidade Estadual Paulista "Júlio de Mesquita FiIho", Rio Claro, 1995.

LEITE, C. Cidades sustentáveis, cidades inteligentes. São Paulo: Bookman, 2012.

MELAZZO, E. Mercado imobiliário, expansão territorial e transformações intraurbanas: o caso de Presidente Prudente-SP (1975-1990). Dissertação (Mestrado em Economia) - Instituto de Economia, Universidade Federal do Rio de Janeiro, Rio de Janeiro, 1993.

PEDRO, L. C. Os impactos da expansão urbana sobre os compartimentos geomorfológicos de Presidente Prudente-SP. In: ENCONTRO NACIONAL DA ANPEGE, 8., 2009, Curitiba. Anais... Curitiba: Anpege, 2009. p. 1-16.

PRESIDENTE PRUDENTE (Cidade). Mapas da cidade de Presidente Prudente. Presidente Prudente, 2014. Disponível em: http://www.presidenteprudente.sp.gov.br/site/central_mapas.xhtml. Acesso em: 12 mar. 2015. 
. Lei Complementar n. 153, de 10 de janeiro de 2008. Dispõe sobre a Lei de Zoneamento do Uso e Ocupação do Solo, da Área Urbana do Município de Presidente Prudente e dá outras providenciais. Câmara Municipal de Presidente Prudente, 2008.

RODRIGUEZ, M. M. Planejamento Ambiental como campo de ação da geografia. In: CONGRESSO BRASIlEIRO DE GEÓGRAFOS, 5., 1994, Curitiba. Anais... Curitiba: AGB, 1994. v. 1, p. 582-94.

SOARES, F. B.; LEAL, A. C. Planejamento ambiental da bacia do Balneário da Amizade nos municípios de Álvares Machado e Presidente Prudente - São Paulo. In: FÓRUM AMBIENTAL DA ALTA PAULISTA, 2., 2011, Tupã. Anais... Tupã: Anap, 2011. p. 75-93.

SPOSITO, M. E. B. A Expansão Territorial Urbana de Presidente Prudente. Recortes, Presidente Prudente, n. 4, p. 1-61, 1995. 